\title{
Interpretations of the Pleiades in Australian Aboriginal astronomies
}

\author{
Dianne Johnson \\ Australian Centre for Independent Journalism, University of Technology in Sydney, \\ PO Box 123, Broadway, NSW 2007, Australia \\ email: dijohnson@pnc.com.au
}

\begin{abstract}
As there are so many Australian Aboriginal and Torres Strait astronomies and cosmologies, commonalities are unusual. However one of the 'things belonging to the sky' that seems common to all groups across the continent is the open star cluster of the Pleiades. Yet interpretations of this cluster vary. So far I have tentatively identified four different cultural areas, the first being most of mainland Australia; the second being the islands south of mainland Australia known as Tasmania; the third being the cultural area of north-eastern Arnhem Land; and the fourth being the cultural area of the Torres Strait Islands. Within these areas, versions of the stories vary as contemporary circumstances change.
\end{abstract}

Keywords. Pleiades, Australian Aboriginal astronomies, Arnhem Land, Groote Eylandt, Torres Strait, star mythologies

\section{Varying Australian astronomies}

In order to comprehend the enormous scope of the Aboriginal Australian night sky, it is important to appreciate that prior to the invasion of the continent by Europeans, there were at least as many indigenous astronomies as there were discrete language or cultural groups.

As the Australian land mass constitutes a vast area, straddling some 33 degrees of latitude - from 43 degrees south in Tasmania to 10 degrees south in the Torres Straitthere is obviously a great range of night skies actually visible at any one time across the continent. In addition, there is a great variety of dynamic ecological environments from which they are viewed. It is clear that the particular contexts in which knowledge about the stars was and is still produced differs from one locality to the next and was sustained and modified in response to changing circumstances and social contingencies. There is no doubt that astronomical knowledge was considered to be extremely important, to the extent that it has been described as being one of the 'principal branches of education' (Dawson 1981 [1881]: 12), and was passed on from one generation to the next in accordance with particular rules concerned with its ownership by specific men and women. Astronomical observation and enquiry were not separate areas of knowledge in Australian indigenous groups; they were rather integral parts of everyday life and were reflected in storytelling, song, dance, art and ritual. In other words, the sky, both day and night, was a part of the total sacred landscape.

One way to better appreciate the significance of the night sky to Aboriginal and Torres Strait Islander people is to understand it as a series of multi-layered interconnecting maps, its meanings operating at many levels simultaneously and varying with the particular filters that are overlaid. When, for example, the night sky is viewed as a seasonal calendar, it does not exclude meanings it has in mythologies or social relationships, as these aspects frequently elaborate the seasonal manifestations. It simply represents a shift in emphasis. 
Stars used for seasonal voyaging may also, at the same time, have meanings in a terrestrial landscape. Moreover, knowing them as belonging to the place of the dead, for example, does not preclude seeing them as patterns of living celestial campfires. In addition, the celestial landscape is intrinsically linked with the terrestrial one, as most of the myths that involve the stars have their dramatic starting points or episodes on the earth, so that many sky-based ancestral heroes and heroines are also associated with particular places in the earthly landscape.

\section{Some commonalities}

As there is enormous variation in Aboriginal and Torres Strait Islander astronomies and cosmologies, commonalities are unusual. However, it is possible to identify a few. One of the commonalities across the continent is the existence of a dome-like sky-world, which is seen as the dwelling place of many ancestral spirits and creation heroes and heroines, those personified sources of energy which inform and give meaning to natural and cultural life. The sky-world is a vast, plentiful, and lively place, from which the sky-people can travel along shamanic pathways. Earthly-based men and women of high degree, the traditional healers, whose great powers are seen to be connected to these energies, could also access the sky-world, usually by climbing or pulling themselves up a connecting cord, variously viewed as string, hair, rainbows, spears, grass ropes, trees, flames or via a particular animal (for elaboration, see Johnson 1998: 14-17).

Very few European constellations have a direct Aboriginal or Torres Strait Islander equivalent. In fact, the prevailing idea in European astronomy, of joining the brighter points of light to form patterns, is barely followed in Aboriginal astronomies. The very dark patches between or beside the points of light are frequently distinguished, with some joined up to create vast black constellations that spread out and cover much of the night sky. Coloured and moving stars were distinguished, as was the case with the Victorian Boorong people, for whom a star's relation lineally to the horizon marked its significance (MacPherson 1881). A star's position in relation to the Milky Way is significant to many groups because the Milky Way delineates moiety equivalences whereupon skybased marriage classes and 'skin' groups were assigned (Maegraith 1932).

\section{The Pleiades}

There is however, one star cluster that is significant across the length and breadth of the Australian continent, to Aboriginal and Torres Strait Islander peoples, as well as to many non-Aboriginal people - the Pleiades.

It seems that the Pleiades were distinguished as a separate cluster, by nearly all Aboriginal nations in the country, but the ways in which they were and are interpreted varies.

Given their significance, it seemed fitting that the 'Dance of the Pleiades' was performed by Pitjantjatjara Aboriginal women from the Central Desert at the Opening Ceremony of the Sydney Olympics in September 2000. However, when you are out camping 'in the bush' in Australia, you know that the Pleiades women have visited your camp overnight when you wake up with an extremely cold nose and the canvas of your swag covered in white icy crystals. The Pleiades women first appear in the southern hemisphere in the early hours of the morning and they flamboyantly sweep across the sky excreting frost. 


\section{Cultural interpretations and locality}

Within the Australian context, the way that the cluster is interpreted depends on its location. At least four distinct cultural areas can be distinguished: most of mainland Australia; the islands of Tasmania; the cultural area of north-eastern Arnhem Land including Groote Eylandt; and the cultural area of the Torres Strait Islands.

The image of the Seven Sisters, travelling together across a landscape, hastening away from the unwelcome advances of a man, is an archetypal motif. The archetype is firmly lodged in many cultures, with the motif of the fleeing women being highly associated with the Pleiades. The story has captured the human imagination for as long as we have been looking up and trying to make sense of the night. This exquisite cluster is as significant in the mythologies of Australian Aboriginal and Torres Strait Islanders as it is to those whitefella-Australians who know the night sky and so choose to live their lives still steeped knowingly or unknowingly in the mythologies of the ancient Greeks and Romans.

\subsection{Mainland Australia}

Over most of mainland Australia, the Pleiades are viewed (with a few exceptions, see Johnson 1998: 55; Clarke 1997: 136) as a group - five, six or seven in number - of related ancestral women.

In the majority of narratives, the central motif involves usually seven sisters running away from, or six trying to help one of their younger or more vulnerable siblings to get clear of, the unsolicited and usually illicit advances of a man or group of men. The man (or men) is usually represented as the (European) constellation of Orion, although there is some variation in the celestial object that is assigned the role of the assailant. There are instances in which the celestial pursuant is the moon, or the stars known as the Gemini Twins (Castor and Pollux), or the stars of the Southern Cross, or the coloured star of Aldebaran, or the Morning or Evening Star (Planet Venus), or the bright star, Canopus. All these celestial objects rise after the Pleiades and consequently follow their path across the night sky. The pursuing man (or men) is frequently portrayed as a trickster who can disguise himself and creep up on the women in the form of an animal.

Anthropologist and prehistorian Isabel White (1975) had the opportunity of observing on several occasions, the dramatisation of the Seven Sisters narrative by Andagarinja women from Yalata and Indulkana in South Australia. The narrative was associated with the Seven Sisters Ceremony and the celebration of initiation rites performed by women for a girl during her seclusion away from the main camp. White was told a version of the story by the acknowledged ritual leader of the women, who was also the designated 'boss' of the ceremony. This particular woman recited and acted the part of Njuru, the constellation of Orion, who chased the seven ancestral women, the Pleiades, across vast tracks of (Western Australian) country - through Meekatharra, Wiluna, Laverton, Kalgoorlie to Cuneelee, where the women hid in a cave. But Njuru caught one of the women and raped her. Because of the incestuous nature of the act as the woman was Njuru's (classificatory) father's sister, she became ill and died. The other six women continued on with Njuru in hot pursuit, until they reached Anmanggu in the Musgrave Ranges where they set up camp. Njuru sent his penis underground to, again, rape one of the women. But this time, the women set their dogs onto the penis, which in the ensuing fracas, was severed and became a separate entity known as Jula.

This particular version of the story extends from areas west of the Warburton Range in Western Australia, over the Rawlinson, Mann and Musgrave Ranges, reaching the Centre (Glen Helen Gap in the Western MacDonnell Ranges), where in the rocks at the side of 
the Finke Gorge, the women cluster together in fright. The vertically embedded rocks at the mouth of the gorge are believed to have been created by the feet of the dancing Pleiades - women as they performed a women's ceremony before escaping into the skyworld. From accounts by Tindale (1959), this version also extends south to Ooldea in South Australia and north to Haasts Bluff and Yuendumu in the Northern Territory.

There are variants of this story in many other places across the continent, and in essence, they traverse thousands of kilometres of country as several separate narratives.

Hundreds of localities feature in great song cycles that are still maintained and performed regularly, particularly in the Central and Western Deserts. Other sources extend this song cycle into Queensland, into the mouth of the Murray River in South Australia, in many places around New South Wales including the North Coast, the Western Plains and the marginal desert country. It is very apparent that the Seven Sisters story spans thousands of years, linking sites and people across the continent.

It is noticeable that Seven Sister sites, even in desert country, are always places where particular bush foods are growing or places where there is water available in some form.

In some places, rock art sites are still regularly over-painted and used for ceremonial purposes associated with the Seven Sisters narratives. White (1975) indicates that men's versions of the narrative differ from the women's, but the myths generally concern gender relations and reflect the open antagonism between the sexes that exists in cultures whose values she sees as being 'primarily male dominated'.

As the Pleiades rise in late autumn, they are significant indicators of weather change and in many areas, they signal the onset of the coldest nights. For the Adnyamatana people of the Flinders Ranges, the icy weather of the Pleiades women also indicates the malkada-time, the time of initiation for boys (Tunbridge 1988: 16), and they saw the Pleiades women as having (kangaroo) pouches filled with fine white crystals which streamed from them as they crossed the sky (Mountford: 1939: 103-104). People in areas around inland New South Wales and the Queensland border areas saw the Pleiades women as frequent urinators, also leaving a trail of ice (or frost) before dawn (Mathews 1982: 13-14). In the Western Desert, when the cluster rises (in late autumn), the coming of the dingo pups is indicated and also, the beginning of a new cycle. The coming of the dingo pups arrives earlier in Arnhem Land, and Orion, rising at dawn (about June), signals this propitious event (Elkin 1974: 32).

Munya Andrews, a Bardi woman from the Western Kimberley, has written extensively about the Pleiades (Andrews 2004). She was told the Seven Sisters story of the Pleiades by her grandmother. It was her grandmother's favourite story. It has become Andrews' favourite story as well, and she remembers that her grandmother "spoke about them (the Seven Sisters) ... with such warmth and love, ... and she'd often tell me that 'You know, Munya, they're our relatives, they're our countrymen up in the skies' " (ABC Radio National 2004).

The Pleiades sisters are also frequently incarnated in earthly rather than celestial environments as female birds. In the Blue Mountains and Southern Highland areas of New South Wales, for example, the Pleiades were visualised by the Gundungurra people as a family of young female white-winged choughs or jays, who frequented the bush in search of yams and herbs (Shepherd 2003: 19, 26). Not only did the moon constantly pursue the women but, as well, the black-and-white male magpie was always dodging after them hoping to make one of them his wife. After the magpie rescued one of the choughs from a waterhole, she consented to marry him. But the magpie was a lazy fellow and made the chough and her sisters do all the work around his camp. They often tried to steal away from him but he always followed their tracks and brought them back. One day as a storm threatened, the women asked the magpie to strip some bark off a 
stringy-bark tree to make a shelter. He refused, so the wife began to do it herself. As she pulled the bark sheets upward, her sisters sang a charm song to help her with her work and to make the tree grow taller. She kept stripping the bark, all the time climbing higher and higher. The white-winged chough sisters followed, stripping the bark right up to the sky, where they have remained as the Pleiades ever since.

\subsection{Tasmania}

There is no doubt that the Aboriginals from the islands of Tasmania (including the Furneaux in Bass Strait) had star myths embedded within an elaborate cosmology. So far, no old myths or legends that refer specifically to the Pleiades have surfaced. It seems unlikely that Tasmania is one place that had and still has no stories connecting it to the Pleiades; possibly they will come to light further down the track.

\subsection{Arnhem Land and Groote Eylandt}

Within the cultural area that covers northern Arnhem Land and Groote Eylandt, although still ancestral women, the Pleiades women are viewed somewhat differently. They are seen as partners of their fishermen-husbands who are represented as stars in the constellation of Orion. Indicating the significance of voyaging by canoe, the Pleiades and Orion are part of an Arnhem Land constellation known as Tjirulpun (sometimes 'Tjulpan', also known as the canoe stars) which includes the Hyades and many of the bright stars north and south of these groups. In some versions of the story, the ancestral women's canoe is pursued by that of the men (Spilia 2010: 119).

Coming from this area, Gulumbu Yunapingu, an artist whose amazing star designs were unveiled at the Musée du quai Branly in Paris in 2006, has recently been commissioned to incorporate her Yolngu starscapes into the centrepiece of the Australian National University's new building for studies in Asia-Pacific diplomacy and allied studies. Yunapingu regards each of her paintings "as a fragment of the whole, part of a performative documentation of the apparently expanding universe" (Spilia 2010: 119). She says that she found the story of the constellations from the sacred songs that her father (Munggurrawuy Yunupingu) used to sing:

"... We grew up listening to him sing about them. Every day at dawn he would sing until the sun came up. When he saw the first glow before dawn he would start to sing the Djulpan constellation. He would sing these stars. That is the story that came from him.

I have left alone the Djulpan costellation... Lots of tribes have songs of the Djulpan constellation. Only a few tribes have the right to sing this story of those constellations but it is sacred to them, to us. I found it better painting the stars of the universe because it does not belong to anybody and it is not sacred, anyone can paint it." (Perkins 2010: 262).

The Tjulpan or canoe stars, which include the Pleiades, are visible during the wet season, when the fishermen paddle their canoe along the sky-river, the Milky Way, whilst their wives paddle a separate canoe. Both groups, so the story goes (Mountford 1956: 493, 498-500), have caught many fish out at sea, but, when nearing Cape Arnhem, a heavy storm swamps both canoes, all the occupants drown. The two canoes, the men, the women, turtle, fish and a whale they had caught are now in the night sky. Knowledge of tides and winds as well as seasons indicated by stars is obviously significant for the successful preparation and undertaking of fishing and canoeing.

\subsection{The Torres Strait}

The fourth cultural area that can be distinguished extends over the islands of the Torres Strait. Living in an island-sea environment, Torres Strait indigenes identify with the sea and much energy goes into the preparation for voyages for the purpose of exchange by 
outrigger-canoes between the islands and the mainland coasts of Papua New Guinea and Australia. On the island of Mer (Murray Island) in the eastern Torres Strait, for example, the Meriam people set out on their long sea voyages when the Pleiades appear as a sign of fair weather, around mid-October. Shell armlets (wauri) are ritually given between exchange partners and, in addition, yams, bananas and sweet potatoes mixed with turtle fat, roasted, dried and placed in sealed bamboo tubes are packed into the canoes. Having reached Papua New Guinea, these goods are exchanged for bird of paradise and cassowary feathers, and dog's teeth necklaces. Between Mer and Cape York, red and white ochres, emu feathers and emu leg bones for digging sticks are sought in similar exchanges. These expeditions are exceptionally dangerous and follow a path from east to west like the one taken by the stars: ". . life mirrors the crescent shaped path of the stars of Tagai, from springtime when Seg (Orion) and Usiam (the Pleiades) come up to the time of their decline" (Sharp 1993: 78).

The Tagai (or Togai) is a mythical ancestral hero who belongs to all Torres Strait Islanders. He is represented in the night sky as an island man standing in a canoe. In his left hand, he holds a fishing-spear, the three pronged head of which is represented by the Southern Cross. In his right hand he holds an apple-like fruit, represented by the Western constellation of Corvus the Crow. The immense constellation of the Tagai consists of Sagittarius, part of Telescopium, Scorpius, Lupus, Centaurus, part of Hydra and one star of Ara. As well, there are twelve crewmen, six of whom are represented by the Pleiades group and the other six represented by the stars in the belt of Orion (Sharp 1993: 3, 4). The narrative tells the story of Tagai and his twelve crew who stole the food and drink which had been prepared for a voyage. As a result, they (Usiam, the Pleiades and Seg, the belt of Orion) were all thrown overboard into the sea by Tagai, their images set into star patterns forever. The stars of Tagai usher in seasonal and ceremonial changes and act as a guide to navigational voyaging, cultivation and fishing. In addition, the Tagai represents the charter for the Meriam people, to follow their own cultural traditions inherited from their forebears, and which, in the course of time, they must pass on to following generations:

"The pattern of (Meriam) social life ... is written in their layout of the stars. Its movement is inscribed in their trek across the sky. The pattern of the stars becomes the language of a cultural statement" (Sharp 1994: 6).

During the much celebrated Mabo Case, which concluded on 3 June 1992 with a resounding victory for the Meriam people according them native title to the island of Mer, extensive evidence was taken by the court about traditional law concerning the continuity of land ownership as set down by Malo, an ecologically-oriented spirit ancestor. Malo's Law includes laws against trespass, laws about keeping to one's secret ways, laws prescribing that the land be productive under cultivation, and laws demanding that unneeded fruit be left to drop to the ground. Most of the plaintiffs delivered the allegorical invocation 'Stars follow their own path...', when asked about land tenure, succession and trespass, as the invocation addresses all three (Sharp 1994: 7). The invocation is inspired by the constellation of the Tagai, and, as a corollary, the Meriam must not trespass or encroach on what does not rightly belong to them. In the invocation that was presented to the High Court as evidence of their ongoing cultural ties, the Pleiades was cited as a powerful symbol having its own time, space and rhythms:

"I cannot walk the path that is Usiam's (the Pleiades) nor can I walk the path that is Seg's (Orion) ... for I must follow teter mek, the footprints made by my ancestors" (Sharp 1993: 71). 
The stars for the Meriam people have their own pathways across the heavens, each star having its own journey to make, as does everything in the cosmos: its own time, its own place and its own destiny to fulfil.

\section{Conclusion}

Within three of these four broad cultural areas in Australia, the Pleiades star cluster, in combination with other single stars and constellations, provides an intriguing continuity in Australian indigenous cosmologies and is clearly significant throughout the country.

\section{References}

ABC Radio National 2004, 'The Seven Stars of the Pleiades', on The Spirit of Things (10 October 2004) (http://www.abc.net.au/rn/relig/spirit/stories/s1213298.htm).

Andrews, M. 2004, The Seven Sisters of the Pleiades: Stories from around the World, Spinifex Press, Melbourne.

Clarke, P. A. 1997, The Aboriginal cosmic landscape of Southern Australia. Records of the South Australian Museum, 29(2), 125-145.

Dawson, J. 1981 [1881], Australian Aborigines: the Languages and Customs of Several Tribes of Aborigines in the Western District of Victoria, Australia, Australian Institute of Aboriginal Studies, Canberra.

Elkin, A. P. 1974 [1938], The Aboriginal Australians, Angus \& Robertson, Sydney.

Johnson, D. 1998, Night Skies of Aboriginal Australia: a Noctuary, Oceania Monograph 47, University of Sydney, Sydney.

MacPherson, P. 1881, Astronomy of the Australian Aborigines. Journal and Proceedings of the Royal Society of NSW 15, 71-80.

Maegraith, B. G. 1932, The Astronomy of the Aranda and Loritja tribes, Transactions of the Royal Society of South Australia 56, 19-26.

Mathews, J. 1982, The Two Worlds of Jimmy Barker, Australian Institute of Aboriginal Studies, Canberra.

Mountford, C. P. 1939, An Anyamatana legend of the Pleiades. Victorian Naturalist 56, 103-104.

Mountford, C. P. (ed.) 1956, Records of the American-Australian Scientific Expedition to Arnhem Land, Vol 1: Art, Myth and Symbolism, Melbourne University Press, Melbourne.

Perkins, H. 2010, Art + Soul: a Journey into the World of Aboriginal Art, The Miegunyuh Press, Carlton, Victoria.

Sharp, N. 1993, Stars of Tagai: the Torres Strait Islanders, Aboriginal Studies Press, Canberra.

Sharp, N. 1994, Malo's Law in Court: the Religious Background to the Mabo Case, The Charles Strong Memorial Trust, Adelaide.

Shepherd, J. 2003, Legends of the Blue Mountains Valleys, retold by F. Walford, ed. J. Smith, Den Fenella Press, Wentworth Falls.

Spilia, E. 2010, Gulumbu Yunapingu: into the light. Art \& Australia 48(1), 118-123.

Tindale, N. B. 1959, Totemic beliefs in the Western Desert of Australia, Part 1: Women who became the Pleiades. Records of the South Australian Museum, 13(3), 305-332.

Tunbridge, D. 1988, Flinders Ranges Dreaming, Australian Studies Press, Canberra.

White, I. M. 1975, Sexual conquest and submission in the myths of central Australia. In L.R. Hiatt (ed.), Australian Aboriginal Mythology, Australian Institute of Aboriginal Studies, Canberra, pp. 123-142. 